\title{
APOBEC1 Complementation Factor
}

National Cancer Institute

\section{Source}

National Cancer Institute. APOBEC1 Complementation Factor. NCI Thesaurus. Code C143033.

APOBEC1 complementation factor (594 aa, $\sim 65 \mathrm{kDa}$ ) is encoded by the human A1CF gene. This protein is involved in binding to and metabolism of APOB mRNA. Missense mutations in the gene may be associated with melanoma and other neoplastic diseases. 